\title{
The Deinstitutionalization and Fragmentation of the Swedish School System
}

We showed in the previous chapter how the view of knowledge in the Swedish school system radically changed between the end of World War II and the early 1990s. Through the successive reform of national curricula, the postmodern social constructivist view of knowledge was established as the dominant thought style. We continue exploring that subject in this chapter, demonstrating that in practice, nothing has changed in recent years. We begin by showing how profound structural changes to the school system have exacerbated the already hazardous incentives created by the stipulated view of knowledge. The analysis of those incentives is mostly left to the penultimate chapter; here, we describe the recent sea change that has occurred in the organization of Swedish education.

Broadly speaking, it is possible to distinguish between three different periods in elementary and secondary education in Sweden, the first of which started with the Elementary School Act of 1842. ${ }^{1}$ At that time, local parish administrations were given the responsibility to provide elementary schooling to the Swedish population. Most secondary education institutions were also connected to the Church. Starting at the turn of the century, however, the state strengthened its presence in elementary and secondary schooling, initiating a prolonged period of education centralization in Sweden.

\footnotetext{
${ }^{1}$ Skott (2015).
}

(C) The Author(s) 2022

M. Henrekson and J. Wennström, Dumbing Down, https://doi.org/10.1007/978-3-030-93429-3_7 
In 1919, as previously explained, the first truly national curriculum was introduced, and in 1920, a central school authority, the Swedish National Board of Education, was established and given responsibility for both mandatory elementary school and college-preparatory school (later extended to include all secondary schooling). Although the management of schools still occurred at the local level, central government regulations grew increasingly binding, and earmarked intergovernmental transfers constituted an increasing share of school financing. ${ }^{2}$

The enactment of the unity school, the enhetsskola, in the early 1960s meant not only that all children studied together for nine years but also that the state (the central government, parliament, and relevant government agencies) was attempting to assume total control over the form and content of the Swedish school system.

The Swedish National Board of Education had 24 regional branches commissioned to oversee school management. This included the recruitment of teachers, principals, and deputy principals based on strict government rules regarding merit and salaries and ensuring that all schools in their jurisdiction adhered to the detailed, centrally determined course syllabi and times allocated to the different subjects.

In order to receive the intergovernmental transfers, every school had to submit a detailed report of its activities to the regional agency, which had the right to make unannounced inspections of individual schools at will. Moreover, a government agency reviewed and approved all textbooks to ensure correspondence between the centrally determined course syllabi and the teaching material, ${ }^{3}$ and a national relative grading system was calibrated at the class level using standardized test results.

By 1970, the centralization project was completed, and the school system was de facto managed by the state, which tightly controlled the structure and content of education as well as the salaries and competence requirements of teachers and principals. With the exception of those students attending a select handful of independent schools, ${ }^{4}$ all Swedish children between the ages of 7 and 16 went through exactly

\footnotetext{
${ }^{2}$ Lindbom (1995); SOU 2014:5, pp. 47-48.

${ }^{3}$ Over the years different agencies fulfilled this role, and their responsibilities varied somewhat (Johnsson Harrie, 2009).

${ }^{4}$ Less than one percent attended independent schools (Jordahl and Öhrvall, 2013), which essentially taught the children of the wealthiest families or had alternative pedagogic profiles; these schools were only partially supported by funds from the state.
} 
the same school system (the only variation was the option to study English, mathematics, and either French or German at a somewhat more advanced level in grades 7-9 and the possibility to opt out of studying a second foreign language). Likewise, secondary school was basically identical everywhere, with a number of two-year vocational programs and five three-year college-preparatory programs (students in technology programs had the option of adding a fourth year to obtain a lower-level engineering diploma).

This system remained largely unchanged until the late 1980s and early 1990s, when a number of far-reaching reforms were instituted by governments on both sides of the ideological spectrum, shifting the system into the third and present period of decentralization and marketization. In the course of just a few years, the school system went from being arguably the most regulated in the entire OECD to being the polar opposite. ${ }^{5}$

\section{Governance Transferred to Municipalities}

In 1989, the Social Democratic government passed the so-called Governance Bill, ${ }^{6}$ which reduced the role of the central government in education to merely setting general goals and objectives while transferring the responsibility for primary and secondary schooling to the municipalities. It had been a long-term goal of the Social Democrats since the 1970s to move the democratic governance of the welfare state down to the municipal level- "close to the citizens" - and in the late 1980s, this ambition harmonized with the zeitgeist. ${ }^{7}$ One example is the trend toward decentralization and management by objectives that swept through public administration in Sweden and the West more broadly. Another is the critique leveled by both the Right and a neoliberalized Left at perceived bureaucratic rigidities, limited individual choice, and financial waste in the centralized public sector. Increasingly the Social Democrats had come under the sway of such complaints and sensed that something had to be done to reform the strong state.

In the area of education these disparate political priorities were consolidated in a more or less complete decentralization and deregulation of

\footnotetext{
${ }^{5}$ SOU 2014:5, p. 57.

${ }^{6}$ Government Bill 1988/89:4.

${ }^{7}$ Ringarp (2011, p. 194).
} 
the school system, which only began with the transfer of administration and management of all public schools to Sweden's 290 municipalities. ${ }^{8}$ Effective from 1991, teachers and school principals became municipal employees, and the strict merit and experience-based salary schedules were abandoned and replaced by individually negotiated salaries. Other previous regulations on teaching were also repealed; for example, subjectspecific academic qualifications were no longer required for teachers. ${ }^{9}$ Teaching became more of a regular job, in line with new public management (NPM) reform ideas. ${ }^{10}$ Moreover, intergovernmental transfers were no longer tied to adherence to detailed rules regarding staffing, syllabi content, or the time allocated to the different subjects. Instead, each municipality received a lump sum from the central government based on the number of inhabitants aged 6-20 years, and this money could also be spent on other municipal activities.

At the same time, the old National Board of Education, which was viewed as an obstacle to the realization of a new, deregulated, and decentralized education system and contrary to social democratic education policies in general, ${ }^{11}$ was abolished and replaced by the National Agency for Education. However, the agency was not primarily a regulatory agency. In fact, the new agency defined itself in opposition to the abolished National Board of Education and pledged to "dismantle traditional supervision and control." 12 Its managers expressed a direct disregard for the institutional memory of the previous organization and its first director general, Ulf P. Lundgren, publicly voiced fears that the former board's "bureaucracy was stuck to the walls" of the newly created agency. ${ }^{13}$

The primary task of the National Agency for Education was reduced to collecting information and performing analyses, and the agency did not consider it to be their responsibility to give strong recommendations or authoritative advice to the 290 municipal school administrations. Instead, it was believed that the agency's research into "good examples"

${ }^{8}$ Government Bill 1988/89:4.

${ }^{9}$ This requirement was not reinstituted until 2011 (Government Regulation 2011:326).

${ }^{10}$ See our discussion in Chapter 4.

${ }^{11}$ Haldén (1997).

${ }^{12}$ Haldén (1997, p. 17).

13 Kornhall (2013, p. 51). 
of successful schools would inspire schools to improve themselves and that this would ultimately function as an indirect form of regulation. ${ }^{14}$

Thus, the 290 municipalities were largely left to their own devices when they, almost overnight, found themselves responsible for the management of more than 99 percent of all primary schools and more than 90 percent of all secondary schools. The problems arising from the lack of structure were exacerbated by the fact that the government agency that reviewed all textbooks was abolished in $1991^{15}$ and that school principals were no longer required to be certified teachers. The latter requirement had already been lifted in 1986, and since then, virtually any person could become a school principal by virtue of the flexible formulation in the relevant law requiring only that a school principal "had acquired pedagogical insight through education and experience." 16 Paradoxically, this change was instituted at the same time as the pedagogical leadership role of the principal was explicitly emphasized in the governing documents. Moreover, school principals now in certain circumstances have the right to reassess grades irrespective of their own formal qualifications and knowledge of the subject in question.

\section{The Voucher School Reform}

It was into this debilitated institutional setting that the so-called free school reform was introduced by the Center-Right government led by the Moderate Party that gained power in late 1991. ${ }^{17}$ The reform, the rapid and radical nature of which was criticized by the OECD at the time, ${ }^{18}$ instantly converted all elementary (from 1992) and secondary schooling (from 1993) into a contestable quasi-market. Students and parents were endowed with vouchers amounting to a minimum of 85 percent of the average municipal cost per student, which was increased to 100 percent by the Social Democratic government in 1997 in exchange

\footnotetext{
${ }^{14}$ Haldén (1997).

15 Johnsson Harrie (2009).

${ }^{16}$ SFS 1985:1100, 2 kap. 2 \$. In Swedish: "Som rektor får bara den anställas som genom utbildning och erfarenhet har förvärvat pedagogisk insikt."

${ }^{17}$ Government Bill 1991/92:95 and 1992/93:230.

${ }^{18}$ OECD (1992).
} 
for independent schools abandoning limited student fees, which had originally been allowed. ${ }^{19}$ The voucher was then awarded to the school of the student's choice, while the producer side was opened up to virtually any nonprofit or for-profit organization interested in running a school. It was a predictable extension of the Social Democratic decentralization reform: After 1989 there was no longer just one principal in charge of all schools, i.e., the state, but 290 principals, i.e., the municipalities. With such a multitude of principals already in place, it was made easier to defend a reform that opened the door to even more principals. It was also the case that the knowhow of running a school was lacking in most municipalities and this void had resulted in a need for private actors.

In other words, the stage had been set for a reform that the Moderate Party had planned to implement since the mid-1980s, if elected to power. $^{20}$ The main source of inspiration was Milton Friedman's voucher scheme as presented in his 1980 book with Rose Friedman, Free to Choose. In line with the public choice school of economics led by economists such as James Buchanan and Gordon Tullock, the Friedmans were critical of government monopolies in education and argued that publicly run schools serve the personal interests of teachers and administrators rather than those of parents and pupils, who must conform to the bureaucracy's goals. To counter this transfer of power from "consumers" to "producers" in education, the Friedmans proposed giving vouchers to pupils and thus the freedom to choose among schools, including those that are privately run. $^{21}$

It is clear from the government bill that the government and the responsible cabinet minister, Beatrice Ask, strongly believed in the beneficial effects of the reform:

The right and the option to choose among schools is an important instrument to vitalize schools. ...[It] will benefit the entire school system. Likewise, I believe that competition between schools with different pedagogies and ownership forms, in turn, can contribute to a rising quality across the school system as a whole... Greater freedom to choose and greater opportunities for schools to develop distinct profiles result in

\footnotetext{
${ }^{19}$ Government Bill 1995/96:200.

${ }^{20}$ Wennström (2020).

${ }^{21}$ Friedman and Friedman (1980).
} 
stronger incentives for cost efficiency. New and more efficient learning methods can be tested and disseminated. A growing share of independent schools may therefore contribute to a more efficient use of resources in the school system at large.

Restrictions on independent schools were (and largely continue to be) few and did not include competence requirements for owners, such as previous management experience from the educational sector, or any restrictions on the right to pay dividends to the owners of the schools or to sell a school under the same terms as any other incorporated business. Perhaps most surprisingly, it was not until 2010 that independent schools became explicitly required to follow the national curriculum. ${ }^{22}$

The only restriction on independent schools was that they had to abstain from "cherry picking" students based on ability or socioeconomic background. Admissions should be strictly based on the order of application. However, this rule could be circumvented with impunity since the queueing records were not (and still are not as of 2021) externally administered. ${ }^{23}$

From a private enterprise perspective, the free school reform was highly successful. This is clear from Fig. 7.1, which shows the share of all students in elementary and secondary schools who attend an independent school. At the time of the reform, the share of students in independent schools was negligible, and growth was initially sluggish; the share was a mere three percent in 1999, but then development exploded. In the fall of 2011, the share of independent schools exceeded one-quarter of all secondary schools and one-eighth of all elementary schools. Since then, the share has continued to rise, although at a slower rate. In 2019/20, the share of independent schools at the secondary level was 33.2 percent and that at the elementary level was 17.0 percent. Since the average size of independent schools is smaller than that of municipal schools, the share of students in independent schools out of the total number of students is lower: 28.4 and $\mathbf{1 5 . 2}$ percent for the secondary and elementary levels, respectively. ${ }^{24}$

${ }^{22}$ Swedish Law 2010:800.

${ }^{23}$ Wennström (2020).

${ }^{24}$ The share of independent schools among secondary schools peaked at 50 percent in 2011-12. One-third of those schools have since been phased out, which is one indicator that unqualified providers were attracted to the sector. As a result, many students 


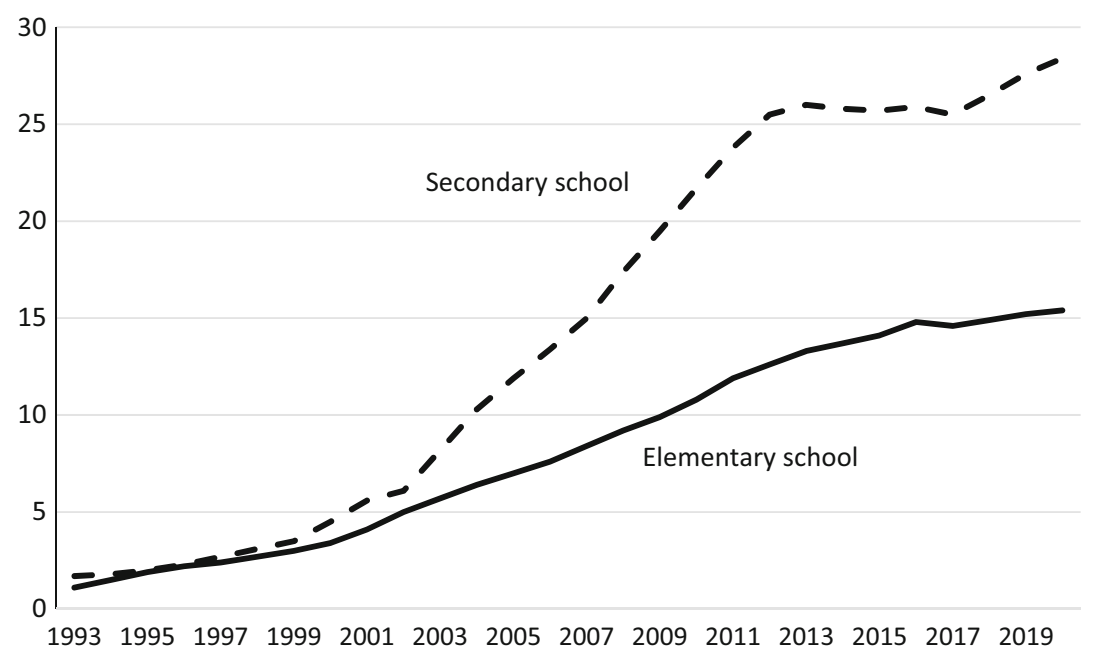

Fig. 7.1 The share of all students in elementary and secondary schools that attend an independent school, 1993-2020 (\%) (Source Swedish National Agency for Education)

Among independent schools, for-profit schools predominate; 76 percent of all students in independent schools attend a school operated as an incorporated firm. In turn, the for-profit school sector is dominated by three large corporations, two of which were public firms listed on the Stockholm Stock Exchange in 2019 (Nasdaq Stockholm). ${ }^{25}$ This largescale standardization and "industrialization" stands in stark contrast to what was envisioned by the Center-Right politicians and opinion leaders pushing for a voucher school system in the 1980s. Rather, they envisioned the emergence of a diverse plethora of small independent schools run by passionate people who wanted to make a difference. ${ }^{26}$

Interestingly, at almost the same time, a school voucher reform highly similar to the Swedish reform was instituted in Milwaukee,

have suffered from substandard educational quality. This is particularly true in regard to vocational schooling at the secondary level.

${ }^{25}$ In late 2020, one of the two company groups, Internationella Engelska Skolan, was delisted, as it was taken over by the private equity firm Paradigm Capital.

${ }^{26}$ Wennström (2020). 
Wisconsin. The arguments for reform were similar in the two contexts, but the outcomes differed greatly. While the Swedish school market became dominated by large-scale for-profit schools, the Milwaukee school program became dominated by small-scale nonprofit schools operated by religious communities. Although for-profit providers were allowed in Milwaukee, only two were started, and both were phased out within a few years. According to one study, the striking difference in outcomes may be ascribed to the deep-seated differences in the civil society regimes in the two contexts. ${ }^{27}$ We elaborate on this point in the next chapter.

\section{The 2OII National Curriculum}

The two radical reforms-the transfer of school governance to the municipal level and the voucher system-had been operative for only two years when the new national curriculum described in the previous chapter was instituted. In line with its postmodern social constructivist view of knowledge, the new curriculum did not spell out explicit course syllabi or knowledge requirements. Guided by a number of general objectives and goals, schools were instead expected to determine at the local level how these goals and objectives were to be practically achieved. An important part of the motivation for this change was the hope that the freedom given to schools to determine the content of education for themselves would force public schools to develop different educational "profiles" and strengthen their competitiveness with independent schools. ${ }^{28}$

The new curriculum also dictated that students should assume successively greater responsibility for their learning; in fact, ensuring that students would be given greater responsibility for and influence over the planning and content of their education was proclaimed to be the teacher's main priority. Statements to the effect that teachers were expected to impart domain-specific knowledge to the students were nowhere to be seen. The teacher's official responsibilities were all concerned in one way or another with supporting self-directed learning and creating a "democratic" classroom environment. Thus, in summary,

\footnotetext{
${ }^{27}$ While the Milwaukee reform was "embedded in a broad and deep infrastructure composed of numerous stakeholders," including advocacy organizations and philanthropic institutions, the Swedish reform was "primarily ideologically inspired and characterized by political top-down decision making" (E. Henrekson et al., 2020, p. 22).

${ }^{28}$ Wennström (2020).
} 
the 1994 curriculum transferred the responsibility for determining the content of and methods for elementary and secondary education from the state to individual schools and their students.

As we have already pointed out, the actual adoption of the postmodern social constructivist view of knowledge and the child-centered pedagogy it entailed was slowed down by the organizational culture and ethos of Swedish teachers, which worked as a "constraint from the past." 29 This old culture was gradually eroded as older teachers retired and were replaced by young teachers trained in accordance with the new orthodoxy.

The Center-Right Liberal Party, particularly its leader Jan Björklund (2007-2019), had been criticizing Swedish schools for the lack of focus on knowledge acquisition, structure, and discipline at least since the mid1990s, even managing to establish a term for this state of affairs: "the fuzzy school" (flumskolan). In the 2006 election, a Center-Right fourparty coalition came to power and Björklund became Minister of Schools, a position he held until $2014 .{ }^{30}$ Thus, he was in a perfect position to realize his party's vision as spelled out in its program:

The level of education is lower in Sweden than in several comparable countries. A world-class educational system is necessary in order for Sweden to become a leading knowledge nation. This requires that children, adolescents, parents, employers, trade unions, and elected politicians have a positive attitude towards knowledge and competence. ${ }^{31}$

It took more than two years before a government bill on education was produced and passed in parliament. Its title was telling: "More sharply defined objectives and knowledge requirements: New national school curricula." 32 It explicitly stated that:

In order to further increase the clarity and understanding of the different types of objectives in the national curriculum, the government deems that the subject-centered curricula should first and foremost specify the knowledge requirements. The subject knowledge may pertain to both skills and

${ }^{29}$ Pollitt (2008, p. 16).

${ }^{30}$ Between 2010 and 2014 Björklund served as Minister of Education and was therefore in charge of the entire education sector.

${ }^{31}$ Folkpartiet (2003, p. 7).

${ }^{32}$ Government Bill 2008/09:87. 
factual knowledge, and [the requirements] should be expressed in a way that does not impede students' knowledge development in the respective subjects.

\section{The Main Features of the Curriculum}

It took until the fall of 2011 before the new national curriculum for elementary school was implemented. Thus, five years passed from the election of the new government until its school policy became effective.

With the 2011 national curriculum, which is still in effect at the time of writing (September 2021), ${ }^{33}$ the state appeared to have reclaimed some of its former regulatory functions. There are now more detailed course syllabi and grading criteria for each school subject. Thus, in theory, this change should have led to greater consistency across schools. However, a close reading of the curriculum reveals it to be as influenced by the postmodern social constructivist view of knowledge as the 1994 curriculum was.

The 2011 curriculum had an almost identical formulation to the 1994 curriculum which stated that "promot[ing] learning presupposes an active discussion in the individual school about concepts of knowledge." 34 It is noteworthy that the phrase "impart knowledge" in the 1994 curriculum was changed to "promote learning" in the otherwise identical sentence in the 2011 curriculum. The term "learning" is used here strategically to reduce the concept of education to an individualistic activity, decoupled from the traditional teacher-student relationship, in what the Dutch education philosopher Gert Biesta has dubbed the "'learnification' of education." $" 35$

The new curriculum also stated that a "historical perspective" should be applied in all school subjects (p. 11). At first glance, this may sound both intellectually open minded and ambitious, but as explained in the previous chapter, this formulation is a key means by which the postmodern social constructivist view of knowledge, namely, that knowledge

${ }^{33}$ Minor revisions were implemented in 2015, 2016, 2017, 2018, and 2019, but these revisions were inconsequential with respect to the issues analyzed here. See Swedish National Agency for Education (2019c).

${ }^{34}$ Swedish National Agency for Education (2011, p. 12).

${ }^{35}$ Biesta (2009, p. 36). 
is neither true nor untrue, can be imposed. The true goal of this formulation is that students will learn that all knowledge is contestable and that there are no ready answers since all answers/facts are allegedly an outgrowth of or tainted by the historical and/or specific circumstances in which they have come about. ${ }^{36}$

Furthermore, the list of prescribed duties for teachers still did not explicitly mention any responsibility to impart domain-specific knowledge (pp. 14-16). Similar to the previous curriculum, the 2011 curriculum asserted that students should exercise "increasingly greater influence over their education" and the organization of their schoolwork (p. 17). However, the 2011 curriculum went even further in that it emphasized that both parents and students have a "right to exercise influence" over goals, content, and ways of working (p. 10). In fact, the curriculum gave every student the right to veto any classroom task or homework assignment that he or she perceived as too challenging and demand that the teacher produce study materials and assessments uniquely customized to that student. ${ }^{37}$ This change raises the question what a teacher should do if multiple families in the same class make opposing demands and whether there are, in fact, any set goals for the education system if those that are set can be continually altered and renegotiated by parents and students. ${ }^{38}$

A striking illustration of the transfer of power from teachers to students stipulated by the curriculum is the mandatory biannual "individual development dialogue" involving the student, the parents (called guardians), and the student's main teacher (normally called mentor). If students do not receive a written grade, which is typically the case before reaching sixth grade (eighth grade until 2012), the teacher is obliged to provide a written individual development plan. This plan provides the basis for the "development dialogue." Moreover, in recent years, a norm has become established that the "development dialogue" should be led by the student and not by the teacher. Often, this is the case even for seven-year-olds.

Another change that has effectively transferred power from teachers to students is the creation of the Child and School Student Representative,

${ }^{36}$ SOU 1992:94, p. 76.

${ }^{37}$ Helmér (2015).

${ }^{38}$ For their part, teachers are obligated to "take as their starting point that the pupils are able and willing to take personal responsibility for their learning and work in school. ... [and] together with the pupils plan and evaluate the teaching" (Swedish National Agency for Education 2018c, pp. 13-14). 
an arm of the Swedish Schools Inspectorate that was established in 2008 to ensure that schools comply with existing legislation and agency stipulations-including the demands for student and parental influence set forth in the national curriculum. This subagency has substantially lowered the threshold for parents and students to file complaints against schools and teachers. The threat of being subjected to fines and other measures has made it far more difficult for teachers to impose appropriate and effective sanctions against unruly or even violent behavior. Instead, teachers have been called upon to show deference and use dialog to establish "trusting relations" with their students. 39

A cursory reading of the 2011 curriculum, which is just under 300 pages, gives the impression of it being a detailed description of the knowledge content of each school subject. ${ }^{40}$ However, a close reading clarifies that the curriculum in fact stipulates that subjects should not be taught based on a conception of knowledge as objective and verifiable. Consider, for example, the following description of the primary purposes of teaching biology 41 :

Teaching in Biology should aim at helping the pupils to develop knowledge of biological contexts, and their curiosity and interest in getting to know more about themselves and nature. Through teaching, pupils should be given the opportunity to put questions about nature and Man based on their own experiences and current events. In addition, teaching should give the pupils the opportunity to look for answers to questions by using systematic studies and different types of sources. In this way, teaching should contribute to pupils developing their critical thinking over their own results, the arguments of others and different sources of information. Through teaching, pupils should also develop an understanding that statements can be tested and evaluated by using scientific methods.

Teaching should give pupils opportunities to use and develop knowledge and tools for expressing their own arguments and examining those of others in contexts where knowledge of Biology is of importance. As a result, pupils should be given the preconditions to manage practical,

${ }^{39}$ Swedish National Agency for Education (2018d).

${ }^{40}$ The analysis in the remainder of this subsection draws on Enkvist (2017).

${ }^{41}$ Swedish National Agency for Education (2011, p. 105). Note that the agency uses the term "pupil" in the official translation, while we use the term "student" throughout. All quotations are verbatim from the official translation made by the agency itself. 
ethical, and aesthetic situations involving health, use of natural resources and ecological sustainability.

Teaching should also contribute to pupils developing familiarity with the concepts, models, and theories of Biology, as well as an understanding of how these are developed in interaction with experiences from studies of nature and people. In addition, teaching should contribute to pupils developing the ability to discuss, interpret and produce texts and various forms of aesthetic expressions with scientific content.

Teaching should create the conditions for pupils to be able to differentiate between scientific and other ways of depicting the world. Through teaching, pupils should get an insight into the worldview of science with the theory of evolution as a foundation and get perspectives on how this has developed and what cultural impact it has had.

This general and highly abstract description does not dwell on the specific biological knowledge students are expected to learn. Instead, the description emphasizes that students should ask questions and seek answers based on their own subjective experiences, learn to express their thoughts verbally, and develop a critical mindset. ${ }^{42}$ When the text, almost en passant, mentions "familiarity with the concepts, models, and theories of Biology" in the third paragraph, exactly what students should know and how the level of their understanding should be gauged are not clearly defined.

The reason for this vagueness may be found in the official commentary on the biology course syllabus. The commentary explains that "concepts, models and theories are the result of people's observations and thoughts," and "because theories have been developed in social and cultural contexts, they are changeable," making biology an "open and creative enterprise." 43 Thus, according to school authorities, there exists no objective knowledge of biology that can be acquired and subjected to examination and grading. Analogous and thus highly similar conceptualizations are presented for physics and chemistry.

\footnotetext{
42 The school system's idea of what constitutes critical thinking is demonstrated in a guide for grading the standardized test on religion in grade 9 issued by the Swedish National Agency for Education (2012b, pp. 29-30). In the guide, it is stated that a student who bases an answer on one single fact-checked source deserves a lower grade than a student who utilizes two subjective sources with differing views on the same topic, thus making them "fair" or neutral when combined in the student's answer.
}

${ }^{43}$ Swedish National Agency for Education (2017b, p. 8). 
Moreover, and in line with postmodernism's emphasis on blurring boundaries, elements from other subjects are incorporated into biology. For example, the goal that students should learn to "manage practical, ethical and aesthetic situations involving health, the use of natural resources and ecological sustainability" seems to belong more in the social sciences than to biology. The goal that students should develop their ability to "produce texts and various forms of aesthetic expressions" appear to be more relevant to the study of their native language and the arts. Other examples of the mixing of disciplines can be found in the subject's "core content," 44 which, for instance, prescribes verbal discussions on "current societal issues involving Biology." The "core content" is supposed to represent the compulsory content of each school subject. However, as the official commentary to the biology course syllabus makes clear, teachers can combine and give different importance to various elements in whatever way they want to. ${ }^{45}$ Hence, the "central content" does not constitute a common core of knowledge.

Furthermore, the statement that students should "be able to differentiate between scientific and other ways of depicting the world" and gain "insight into the worldview of science with the theory of evolution as a foundation" implies that the facts of biology can be described as a "worldview" competing with other equally valid theories. An interview study with teachers does indeed confirm that the theory of evolution is presented in some schools as a worldview on an equal footing with the myth of creation rather than as a scientifically proven fact. ${ }^{46}$

The 2011 curriculum presents all school subjects in this ambiguous way. Critical thinking, verbal expression, and discussion are integrated into every course syllabus, usually in combination with social science perspectives. For example, the art curriculum includes the analysis of pictures dealing "with questions of identity, sexuality, ethnicity and power relations." 47 Physical education and health (formerly called sports) includes "talking about experiences and outcomes from different physical activities and forms of training" as well as discussions about "how

\footnotetext{
${ }^{44}$ Swedish National Agency for Education (2011, pp. 106-109).

${ }^{45}$ Swedish National Agency for Education $(2017 \mathrm{~b}$, p. 10).

${ }^{46}$ Sjögren (2011).

${ }^{47}$ Swedish National Agency for Education (2011, p. 24).
} 
the individual's choice of sports and other physical activities are influenced by different factors, such as gender." ${ }^{48}$ Even the teaching of the students' native language is predominantly focused on verbal communication, and civics is almost exclusively restricted to "reflection," "analysis," and "expressing standpoints." This is congruent with the pattern in postmodernism of encouraging students to "deconstruct" what are perceived as dominant discourses and false truth claims.

With the launching of the above-mentioned Swedish Schools Inspectorate, it has become increasingly difficult to deviate from these prescriptions. During inspections, the agency "ticks off" whether the teachers and the principals have done what the curriculum prescribes. If teachers and principals are deemed not to have complied, the agency will punish schools, e.g., with threats of closure, and demand that they rectify the identified aberrations.

\section{Grading in the 2011 National Curriculum}

That the knowledge content of each subject is deemphasized becomes even more evident when studying the grading criteria, which are "based on the view of knowledge expressed in the curriculum." 49 The grading criteria are entirely subjective and open to interpretation. Consider, for example, these criteria for a passing grade (E) in physical education in ninth grade (bold in original $)^{50}$ :

Pupils can participate in games and sports involving complex movements in different settings and vary and adapt their movements to some extent to activities and context. In dance, and movement and training programs to music, pupils adapt to some extent their movements to beat, rhythm and context.

"To some extent" is replaced with "relatively well" in the criteria for grade $\mathrm{C}$ and with "well" in the criteria for an A (see Appendix A). However, the criteria do not state how, and with what legitimacy, teachers should determine whether a student adapts his or her movements "to some extent," "relatively well" or "well."

\footnotetext{
${ }^{48}$ Swedish National Agency for Education (2011, p. 52).

${ }^{49}$ Swedish National Agency for Education (2017b, p. 29).

${ }^{50}$ Swedish National Agency for Education (2011, p. 54).
} 
This arbitrariness is not exclusive to physical education; it is typical of the grading criteria in all subjects. For instance, the "knowledge requirements" for an $\mathrm{E}$ in biology at the end of ninth grade include the following (p. 112; bold in original):

Pupils can talk about and discuss issues related to health, natural resource use and ecological sustainability, and differentiate facts from values, and formulate their views with simple reasoning and describe some of the possible consequences. In discussions, pupils can put questions, and put forward and respond to views and arguments in a way, which to some extent takes the discussions forward. Pupils can search for information on the natural sciences and use different sources and apply simple and to some extent informed reasoning to the credibility and relevance of their sources and information. Pupils can use information in a basically functional way in discussions and create simple texts and other communications with some adaptation to purpose and target group.

The knowledge requirements for an A in biology use the same vocabulary but with different adjectives, such as "well developed" and "good." Again, and in line with the postmodern social constructivist view of knowledge, it is not clear on what grounds teachers should determine students' grades.

According to the Swedish National Agency for Education (2017b, p. 30), this ambiguity is intentional to ensure that the grading criteria are "manageable" and not unnecessarily strict. However, it is not only the fact that the criteria are subjective that reveal their social constructivist foundation but also that they sometimes demand too much of students, blurring the hierarchy between elementary education and university. Consider the following subcriterion for an A in the students' mother language (bold in original $)^{51}$ : "Pupils can apply well developed and well informed reasoning about the history of the Swedish language, its origins, and special characteristics, and compare these with closely related languages and clearly describe important similarities and differences." The same subcriterion is included even for the lowest passing grade, E, except that

${ }^{51}$ Swedish National Agency for Education (2011, p. 11). 
"well developed and well informed" is replaced with "simple and to some extent." 52

Another illustrative example is the requirements for a $\mathrm{C}$ in civics at the end of the sixth year of elementary school (p. 196; bold in original):

Pupils have good knowledge of different societal structures. Pupils show this by exploring how social, media, legal, economic and political structures in society are organised and function and describe relatively complex relationships in different societal structures.

In a recent study, 33 university professors from a variety of fields, including mathematics and sports, were asked to rank knowledge requirements from different levels in the Swedish educational system spanning from sixth grade (elementary school) to the Ph.D. level. The study found no sign of progression in the requirements, and the professors were unable to identify the level to which the different requirements applied. In some cases, the correlation was even negative; that is, the requirements for the lower levels were deemed to apply to a higher level and vice versa. ${ }^{53}$

Finally, it should be noted that all subjects, including physical education and crafts, ${ }^{54}$ i.e., the production of objects and processing of materials with the help of tools, are intellectualized in the new curriculum. For instance, to obtain a $\mathrm{C}$ in crafts at the end of year 6 , students must be able to (p. 206) "make developed assessments of their own work and how it has affected the quality of their production" and "interpret what a craft artefact expresses and apply developed reasoning about symbols, color, form and material (for an E and an A, "developed" is replaced by "simple" and "well developed," respectively)." To obtain an A in physical education at the end of year 6, students must be able to (p. 54) "talk about their own experiences of physical activities and apply well developed and well informed discussion on how the activities can affect health and physical capacity."

${ }^{52}$ See Appendix A for a complete version of the knowledge requirements in Swedish for grade $\mathrm{A}$ at the end of year 9 .

${ }^{53}$ Sellbjer (2018).

${ }^{54}$ The knowledge requirements for grade $\mathrm{A}$ at the end of year 9 in crafts and physical education are presented in Appendix A. 


\section{Calibration of Grades and National Tests}

Combined with the fact that the grading system implemented in the early 1990s gives teachers full autonomy to assign grades, these ambiguous criteria invite uncertainty about what individual students know. This problem could theoretically be mitigated by the reintroduction of some form of standardized test. Voluntary "national tests" were, in fact, introduced as early as 1997 in Swedish, English, and mathematics in the final year of elementary school and later extended to the third and sixth years of elementary school and the final year of secondary school. Since 2010, national tests have also been administered in the ninth year of the elementary school in the sciences (biology, physics, and chemistry) and social sciences (geography, history, religion, and civics). In 2013, the tests even became mandatory.

However, these tests are marked by a number of weaknesses. First, the tests are typically not taken at exactly the same time in all schools, and as a result, their content is often leaked on the internet, potentially benefitting students at schools administering the test later in the prescribed time window. Second, the tests are sent by regular mail to schools several days in advance and are thus available to the teachers beforehand, which makes it possible to prepare the students by teaching them similar content before the test. Third, and perhaps even more surprisingly, the tests are neither anonymized nor graded by a teacher at another school; they are, in fact, typically graded by the students' own teachers. Fourth, the science and social science tests are given in only one of the subjects, and the Swedish National Agency for Education announces well in advance which two subjects will be tested, thus incentivizing schools to focus on those two subjects to the detriment of the other five. Finally, the tests contain complex essay questions where it is clear neither what the correct answer is nor how detailed a correct answer should be. It is also unclear whether the task is meant to examine the student's level of knowledge or his or her argumentative skills. Here is an example. In the national test in chemistry in year 6 , the students were given the following task:

At school you have discussed why waste should be sorted. The sports club Allsport throws all waste in the same bag. You do not think that is good, and you therefore decide to write a letter to the club. The letter should 
say that the club must improve and why it must improve. In the letter you should use the information in the text below and the film you are about to see. You are allowed to see the film twice. ... Make an argument about why it is important to sort waste by giving arguments in favor of sorting.

The standardized tests in elementary and secondary schools were not centrally collected until 2003 and 2011, respectively, which meant that, before that, there was no external quality control and it was impossible to review past material to verify potential abuse by schools in their grading practices. ${ }^{55}$ Until 2018 , the results of the national tests were merely one of many indicators to help teachers arrive at the correct final grade in the tested subjects. Effective from 2019, national test results became somewhat more binding: "If a student has participated in a national test, the result should be reckoned with in the determination of the final grade. The test result should not be entirely decisive, but one cannot ignore the result, unless there are specific reasons for doing so. ... If the teacher, as a result of the overall grading evaluation, has specific reasons to strongly question the reliability of a student's result on a national test, then the teacher shall not take that result into account." 56 However, aside from the vagueness of that description, there are no forceful sanctions that can be leveled against teachers and schools who award grades that systematically diverge from the results on national tests.

The reluctance of the Swedish National Agency for Education to construct externally valid tests impervious to cheating and ensuring similar grading practices across schools may seem puzzling. However, this is quite understandable given the prescribed postmodern social constructivist view of knowledge and the student-centered learning methods it entails. If knowledge is seen as something subjective that is constructed in a process largely led by the student, this is incompatible with the idea that a student's level of knowledge attainment can be measured externally. Such measurement is possible only if knowledge is considered to be objective and independent of the individual student and if the testing agency clearly defines the body of knowledge to which the test is applied, but this is at odds with the prescribed view of knowledge in the Swedish school system.

${ }^{55}$ SOU 2016:25, p. 125.

${ }^{56}$ Swedish National Agency for Education (2018e, pp. 37-38). 
Instead, the learning process takes center stage, and as a consequence, the grade awarded is not supposed to act as a measure of the level of knowledge attained at the end of a course or by graduation. The main task of the teacher is, therefore, to follow the students' learning process closely, use a number of indicators to gauge the efficiency of the learning process, and in this way, arrive at a grade. In practice, this is done by evaluating numerous aspects of the student's performance in a subject based on so-called knowledge matrices.

Two examples of such matrices are displayed in Appendix B: Swedish and chemistry in grade 9, the final year of primary school. The subject syllabi are broken down into 15 and 14 different components, respectively, and the requirements for each grade (E-A) are spelled out.

In the end, these multidimensional criteria have to be summarized in a single dimension, which requires that the 14 or 15 criteria be weighed together. Reaching a consensus on how this should be done has turned out to be virtually impossible. First, as explained above, the criteria are vague and open to interpretation (which is necessary if they are to be consistent with the prescribed view of knowledge). For instance, what is the difference between "developed and relatively well informed" and "well developed and well informed," which determines the difference between an A and a C for several criteria? Second, a student may be assessed with respect to certain aspects well before the end of the course rather than being evaluated on all aspects at the end of the course. Good mastery of the subject may then not be reflected in the final grade since it can be weighed down by inferior performance on a particular aspect earlier in the course. Moreover, the guiding principles issued by the Swedish National Agency for Education stipulate that a weak assessment of one or two particular aspects early on has a heavy weight on the final grade regardless of the overall level attained by the end of the course. Third, the grades given during the seventh and eighth year are not related to a level calibrated to those years. Instead, it reflects how far the student has progressed relative to the requirements at the end of the final year (grade 9).

Thus, in line with a postmodern social constructivist view of knowledge, subjects are fragmentized, and holistic skills such as reading and writing proficiency are each split into four or more different components. Instead of a final grade consisting of a summative overall appraisal 
of a student's learning at the end of the instructional unit based on the teacher's professional expertise, the assessment is broken down into small parts. In addition to this grading system being onerous and timeconsuming for teachers, it is unrealistic to expect students to understand and operationalize the various subrequirements.

Grading in Sweden is said to be based on an absolutely objective grading system, but the subject syllabi are devoid of detail on the content of assessments, grading criteria are complicated, and grades do not necessarily reflect the level attained at the end of the instruction period. Nevertheless, and although the prescribed view of knowledge is inconsistent with the idea that somebody in a superior position-the state, the school, the principal, or the teacher-defines the body of knowledge against which a student's performance will be gauged, teachers are still obliged to set grades. Oddly enough, students' grade point average from elementary and secondary school is the prime factor for admission to higher education. As we will see, this has been an unfortunate combination.

\section{IN SUM}

We have shown in this chapter how the Swedish school system went from being very strictly regulated to being the polar opposite. In just a few years, one of the most centralized school systems in the world was transformed into an extremely decentralized system almost completely devoid of central directives regarding course content, teaching methods, competence requirements for school principals and teachers, and rules regarding staffing. In addition, the schooling system was marketized, which resulted in a massive transfer of power to students and their parents.

However, one crucial institution in the system remains determined by the central government and its agencies, namely, the view of knowledge. The adoption of the prescribed postmodern social constructivist view of knowledge meant a change in course from a classical view of knowledge, in which the aim is to impart knowledge deemed to be essential for all citizens, to a view in which the process of schooling per se is considered more important than the result. This view emerged in earlier decades, but it did not gain real momentum before the time period covered in this and the previous chapter. It led, not least, to the introduction and perpetuation of a grading system with unclear criteria, no binding national tests, and thus no chance of comparability across schools. 
For an analysis of the implications of these changes and how they gave rise to the problems of falling knowledge levels, inflated grades, and increasing differences between student groups, as well as frustration and distress among teachers and students, we now turn to the next chapter.

Open Access This chapter is licensed under the terms of the Creative Commons Attribution 4.0 International License (http://creativecommons.org/licenses/ by $/ 4.0 /)$, which permits use, sharing, adaptation, distribution and reproduction in any medium or format, as long as you give appropriate credit to the original author(s) and the source, provide a link to the Creative Commons license and indicate if changes were made.

The images or other third party material in this chapter are included in the chapter's Creative Commons license, unless indicated otherwise in a credit line to the material. If material is not included in the chapter's Creative Commons license and your intended use is not permitted by statutory regulation or exceeds the permitted use, you will need to obtain permission directly from the copyright holder.

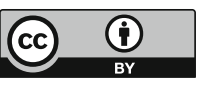

